\title{
Contagious laughter: Laughter is a sufficient stimulus for laughs and smiles
}

\author{
ROBERT R. PROVINE \\ University of Maryland Baltimore County, Baltimore, Maryland
}

\begin{abstract}
The laugh- and/or smile-evoking potency of laughter was evaluated by observing responses of 128 subjects in three undergraduate psychology classes to laugh stimuli produced by a "laugh box." Subjects recorded whether they laughed and/or smiled during each of 10 trials, each of which consisted of an 18-sec sample of laughter, followed by $42 \mathrm{sec}$ of silence. Most subjects laughed and smiled in response to the first presentation of laughter. However, the polarity of the response changed quickly. By the 10th trial, few subjects laughed and/or smiled, and most found the stimulus "obnoxious." Although other research has described canned-laughter effects, it did not consider the hypothesis confirmed here, that laughter itself evokes laughter, perhaps by activating a laughter-specific auditory-feature detector. This result is relevant to the neurological basis of social communication, human ethology, and theories of speech production and perception.
\end{abstract}

"Laugh and the world laughs with you" (Ella Wilcox, 1850-1919) suggests one of the most remarkable properties of human laughter, its contagion. Contagion refers to the tendency of behavior to spread through a group in a chain reaction. Although often trivialized as a curiosity somehow related to humor, contagious laughter may be evidence of a unique and ancient mode of prelinguistic auditory communication that is now performed in parallel with modern speech and language. The study of laughter and its contagion may provide a powerful and convenient approach to evolutionary and neurobiological issues usually associated with analyses of bird songs and animal calls (Provine, 1990; Provine \& Yong, in press).

Call-like laughter has features that should make it attractive to students of language, although laughter is not covered in contemporary reviews of speaking (Levelt, 1989) and listening (Handel, 1989). Laughter is a universal, species-typical component of the human vocabulary (Apte, 1985) and, as such, probably has a strong genetic basis. The species-wide distribution of laughter and its simple, stereotyped structure make laughter ideal for analyses of vocal production and perception (Provine, 1990; Provine \& Yong, in press). The rhythmic, staccato cadence and simple note structure of laughter is more amenable to description and experimental analysis than is more complex, subtle, consciously controlled, and culturespecific spoken language. Laughter has sufficient simplicity and temporal symmetry to pass the reversal test; recordings of laughter played in reverse still sound laughlike except that they proceed with a crescendo instead of the usual decrescendo (Provine \& Yong, in press).

\footnotetext{
The author acknowledges the editorial comments of A. C. Catania. Requests for reprints should be sent to Robert R. Provine, Department of Psychology, University of Maryland Baltimore County, Baltimore, MD 21228.
}

Contagion has received the attention of social scientists from at least the time of LeBon (1895/1960), but most work on the subject has been in the context of sometimes baroque higher level social processes such as deindividuation (Nosanchuk \& Lightstone, 1974), release restraint mediated by imitation, social facilitation, emergence of social norms, conformity, peer pressure, or modeling, none of which do justice to the uniqueness, potency, spontaneity, and biological roots of the phenomenon. (But see Brothers's 1989 treatment of the related concept of empathy.) The power of contagious laughter as a social coupling process is suggested by a persistent epidemic of laughter that began among 12- to 18-year-old girls in a boarding school in Tanganyika and spread throughout a district, requiring the closing of schools (Rankin \& Philip, 1963). Laughter is also a component of contagious glee, a pervasive but less dramatic behavior of groups of young children (Sherman, 1975). Contagious laughter, like contagious yawning (Provine, 1986, 1989a, 1989b; Provine, Hamernick, \& Curchack, 1987; Provine, Tate, \& Geldmacher, 1987), is a powerful, common, and speciestypical behavior that plays a role in social communication and behavior.

Most research relevant to contagious laughter concerns the associated topic of responses to humorous material (McGhee \& Goldstein, 1983a, 1983b). The amount of laughter is correlated positively with group or audience size (Andrus, 1946; Levy \& Fenley, 1979; Morrison, 1940; Young \& Frye, 1966) and whether others are laughing (Brown, Brown, \& Ramos, 1981; Brown, Dixon, \& Hudson, 1982; Chapman \& Chapman, 1974; Chapman \& Wright, 1976; Freedman \& Perlick, 1979), a variable that is often investigated using prerecorded "canned" laughter (Chapman, 1973a, 1973b; Fuller \& SheehySkeffington, 1974; Leventhal \& Cupchik, 1975; Leventhal \& Mace, 1970; Nosanchuk \& Lightstone, 1974; Smyth \& Fuller, 1972). 
Despite the wealth of research on laughter in the context of humor and its social dynamics, it has gone unnoticed that laughter itself may trigger laughter and mediate the phenomenon of contagion. Yet, the laugh-evoking property of laughter contributes to the laugh-producing property of "laugh boxes," "laugh records" such as that produced by OKeh (Demento, 1985), one of the most popular novelty recordings of all time, and the notorious "laugh tracks" of broadcast comedy shows. These are instances of a technology and a commercial product emerging before the scientific implications of the underlying phenomenon were appreciated.

The present research uses prerecorded laughter produced by a laugh box, a small mechanical record player available in novelty shops, to evaluate the hypothesis that laughter is a stimulus for laughter and/or smiles.

\section{METHOD}

\section{Subjects}

The subjects were 128 undergraduate college students in three juniorlevel sensation and perception classes $(n=61, n=49, n=18)$ in which the experiment was a class demonstration.

\section{Procedure}

Ten consecutive 1-min trials, each consisting of an 18-sec sample of laughter followed by $42 \mathrm{sec}$ of silence, were administered to each of three undergraduate classes. The canned laughter was generated by a laugh box, a small mechanical record player of unknown manufacture, provided by a student. (A variety of similar units varying in quality and duration of laughter are available at novelty stores.) The laugh box was activated by the experimenter, who stood at a lectern at the front of a classroom (approximately $9 \times 6 \mathrm{~m}$ ) and held the box about $1.5 \mathrm{~m}$ from the floor with its small speaker facing the class. The stimulus could be heard easily by all subjects. During the 42 -sec silent period between trials, subjects were asked to record on note cards if they laughed (yes/no) and/or smiled (yes/no) in response to the laugh stimulus on that trial. In addition, after the 10th trial, subjects were asked if they found the laugh stimulus to be obnoxious (yes/no). These data are presented graphically without statistical analysis because they do not meet the assumptions of traditional parametric and nonparametric tests for trends.

\section{RESULTS}

A majority of subjects in two of the three groups laughed in response to the laugh stimulus on the first of the 10 trials (Group $1=57 \%, n=49$; Group $2=67 \%$, $n=18$; Group $3=33 \%, n=61$ ) (Figure 1, top). The laugh-evoking potency of the stimulus laughter declined over trials until only 3 of the 128 total subjects laughed on Trial 10 (Group $1=4 \%$; Group $2=0 \%$; Group 3 $=2 \%$ ]. More subjects smiled than laughed in response to the laugh stimulus. Most subjects smiled in response to stimulus laughter on the first trial (Group $1=98 \%$; Group $2=94 \%$; Group $3=85 \%$ ) (Figure 1, bottom), but as was the case with laughter-evoked laughter, laughter-evoked smiling declined over trials, until few subjects smiled on Trial 10 (Group $1=11 \%$; Group 2 $=12 \%$; Group $3=5 \%$ ). The polarity of subjects' responses to the laugh stimulus apparently shifted over trials. Although the question was not asked during earlier trials, after Trial 10, most subjects answered "yes" (Group 1 $=78 \%$; Group $2=71 \%$; Group $3=79 \%$ ) when asked

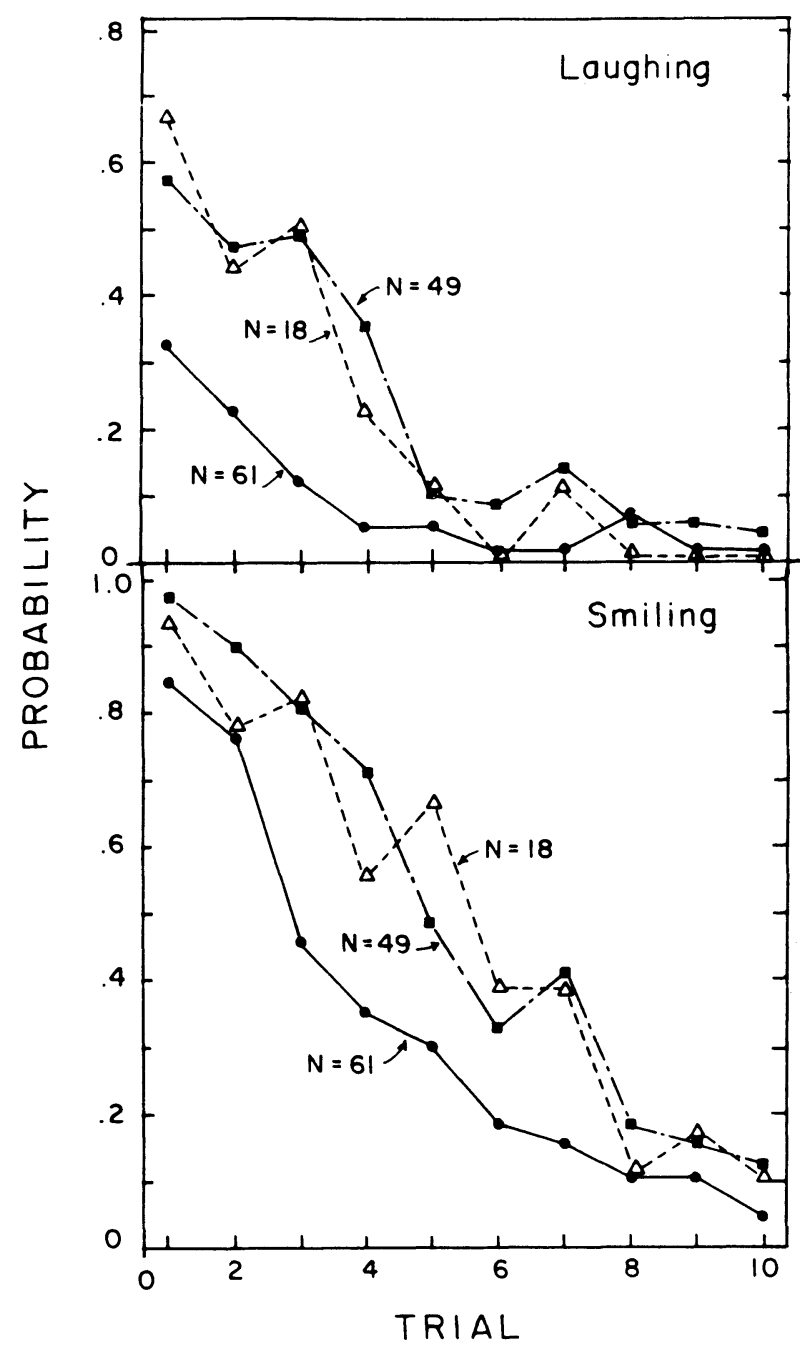

Figure 1. The probability of self-reported laughing (top) and/or smiling (bottom) in response to an 18-sec sample of canned laughter presented during 10 consecutive 1-min trials.

if they found the stimulus "obnoxious." The experimenter (and his colleagues!) can attest to the aversiveness of repeated exposure to canned laughter. He shares his office with several laugh boxes and winces when one is accidentally activated.

\section{DISCUSSION}

Laughter generated by a laugh box was shown here to be a sufficient stimulus for laughter and smiles. This finding builds upon research considered in the introduction that demonstrated the effectiveness of prerecorded "canned" laughter to enhance group and audience laughter and the perceived humorousness of comedy material. However, the earlier work did not consider the hypothesis confirmed here that laughter itself is a potent laugh-evoking stimulus, a result that has significant linguistic, psychological, ethological, neurological, and social implications.

Converging lines of evidence from several disciplines suggest that the contagious-laughter effect is more than a response to a novel stimulus. For example, humans may have evolved a species-typical perceptual process to detect the species-typical vocalization of laughter. In- 
deed, laughter may qualify as an ethological releasing stimulus for the stereotyped, species-typical vocalization of laughter (Eibl-Eibesfeldt, 1989; Provine, 1986). Future psychophysical studies must determine which parameters of laughter (i.e., note structure, note duration, internote interval) are necessary for the perception of laughter and the activation of the hypothetical laugh detector (Provine, 1990; Provine \& Yong, in press). A similar tactic has been pursued in the visual domain to determine the facial features triggering contagious yawning (Provine, 1989b).

Although the existence of detectors specific to features of human speech is debated (Mattingly \& Studdert-Kennedy, 1991), the evolution of a detector for species-typical and sonically simple laughter would be more likely than for complex and culturally variable speech. Contagious laughter is suggestive of an intimate relationship between the vocalization and perception of laughter, an interpretation relevant to the motor theory of speech perception, a position stating that speech perception is somehow related to the act of vocalization (Mattingly \& StuddertKennedy, 1991). Clearly, contagious laughter involves the replication in the perceiver of the motor pattern that generated the original vocalization in the sender.

Studies of laughter and laugh-priming variables considered in the introduction describe the social context of laughter and support the ecological validity of the laugh-evoked-laughter effect. Indeed, contagion may be a central issue in the understanding of laughter, not a footnote. Laughter is probably a relic of an automatic social synchronization process that predates language. The traditional difficulty in discussing the nature of laughter and related matters such as humor is the likely consequence of attempting to reason about a prelinguistic, largely unconscious process of the affective domain. Language, a precision tool of the intellect, may not serve us well in the realm of emotion, empathy, and intuition.

Behavioral analyses of when we laugh escape some of the traditional limits of language and interpretation. The social character of laughter (and by inference, its contagion) was explored by Provine and Fischer (1989), who found that, contrary to common assumption, laughter punctuated ordinary conversations; it was not usually a response to jokes or other formal attempts at humor. Laughter was an almost exclusively social behavior that occurred about 30 times more frequently in social than in solitary situations. (See also Kenderdine, 1931.) Solitary smiling and talking were, by contrast, much more frequent than solitary laughter.

The present finding of a decline in the laugh- and smile-evoking potency of the laugh-box stimulus with repeated presentations until it became obnoxious may seem paradoxical; laughter is usually associated with humor and positive social situations. Although the hypothesis was not tested, the strength of the negative response seemed to exceed what might be expected from the repeated exposure to a generic auditory stimulus and suggests a reaction more specific to laughter. There is indirect support for this proposition. For example, laughter can be derisive in some social contexts. While it is pleasurable to laugh with friends, or laugh at someone else, it is most unpleasant to be laughed at, mocked, jeered, or to be the recipient of an indignant "ha," an isolated note of laughter. Laughter among friends may enhance social cohesion and "in-group" feeling, but to be jeered is to be rejected or cast out of the group, an unpleasant and potentially dangerous consequence. In this context, it is noteworthy that mobbing, a synchronized group response by some birds and mammals to drive often larger invaders from their territories, is functionally akin to human jeering and involves a simple, staccato, repetitive cry similar to laughter (Eibl-Eibesfeldt, 1989, p. 315).

A comparison between laughter and yawning is informative. Both laughter and yawning are species-typical, stereotyped motor acts that show contagion, but they differ in the sensory channel and the latency of their infectious response. The vector of contagion of laughter is auditory, while that of yawning is primarily visual but can be multimodal, including audition (Provine, 1986, 1989b). Although not specifically studied, the latency of the contagious response to canned laughter seems to be almost immediate, at least in comparison to the slow and variable response to visually observed yawns (Provine, 1986).

Contagious laughter generates a parallel contagion of physiological state. Laughter is a vigorous act that has wide-ranging, but only partially known, respiratory (Fry \& Rader, 1977; Fry \& Stoft, 1971), cardiovascular (Fry \& Savin, 1988), and autonomic consequences (Averill,
1969). The physiological correlates may either be passive byproducts of laughter and/or contribute actively to the perception and production of the emotional state associated with the intrapersonal event triggering laughter (see, e.g., Zajonc, 1985). These and other physiological correlates may contribute to the perseveration of laughter, a striking feature of the already-noted Tanganyikan laugh epidemic (Rankin \& Philip, 1963) and an effect well known to those who have experienced the compelling nature of "laugh jags" and to professional comedians who prefer that an earlier act "warm up" an audience. Whatever the physiological correlates of laughter, contagious laughter, like contagious yawning (Provine, 1986), is an example of a social coupling process that synchronizes the biological and behavioral state of a group.

The present analysis argues that contagious laughter is a bizarre and fascinating phenomenon that has important implications for problems at the intersection of the behavioral, social, neurological, and linguistic sciences. Contagious laughter is a reminder that the behavior of modern, rational humans retains prominent, largely unconscious, and poorly understood vestiges of our distant evolutionary past. This message is easy to share with others. Contagious laughter, whether evoked by a laugh box, by the $O K e h$ laugh record (Demento, 1985), or by the laughter of a courageous instructor, provides a reliable, potent, and entertaining classroom demonstration. Canned laughter is also an effective solution to the surprisingly difficult task of evoking the social behavior of laughter in the laboratory.

\section{REFERENCES}

ANDRUs, T. O. (1946). A study of laugh patterns in the theatre. Speech Monographs, 13, 114.

APTE, M. L. (1985). Humor and laughter: An anthropological approach. Ithaca: Cornell University Press.

Averill, J. R. (1969). Autonomic response patterns during sadness and mirth. Psychophysiology, 5, 399-414.

Brothers, L. (1989). A biological perspective on empathy. American Journal of Psychiatry, 146, 10-19.

Brown, G. E., Dixon, P. A., Hudson, J. D. (1982). Effect of peer pressure on imitation of humor response in college students. Psychological Reports, 51, 1111-1117.

Brown, G. E., Brown, D., RAmos, J. (1981). Effects of a laughing versus a nonlaughing model on humor responses in college students. Psychological Reports, 48, 35-40.

Chapman, A. J. (1973a). Funniness of jokes, canned laughter and recall performance. Sociometry, 36, 569-578.

Chapman, A. J. (1973b). Social facilitation of laughter in children. Journal of Experimental Social Psychology, 9, 528-541.

Chapman, A. J., \& Chapman, W. A. (1974). Responsiveness to humor: Its dependency upon a companion's humorous smiling and laughter. Journal of Psychology, 88, 245-252.

Chapman, A. J., \& Wright, D. S. (1976). Social enhancement of laughter: An experimental analysis of some companion variables. Journal of Experimental Child Psychology, 21, 201-218.

Demento, DR. (1985). The OKeh laughing record. Dr. Demento presents the greatest novelty records of all time: Vol. 1. The 1940's (and before) (Rhino Records R4 70820). Santa Monica, CA: Rhino Records.

EIBL-EibesfeldT, I. (1989). Human ethology. New York: Aldine de Gruyter.

Freedman, J. L., \& Perlick, D. (1979). Crowding, contagion and laughter. Journal of Experimental Social Psychology, 15, 295-303.

FRY, W. F., JR., \& RADER, C. (1977). The respiratory components of mirthful laughter. Journal of Biological Psychology, 19, 39-50.

FRY, W. F., \& SAVIN, W. M. (1988). Mirthful laughter and blood pressure. Humor, 1, 49-62.

FRY, W. F., \& STOFT, P. E. (1971). Mirth and oxygen saturation levels of peripheral blood. Psychotherapy \& Psychosomatics, 19, 76-84.

FULLER, R. G. C., \& SHEEHY-SKEFFington, A. (1974). Effects of group laughter on responses to humorous material: A replication and extension. Psychological Reports, 35, 531-534.

HANDEL, S. (1989). Listening: An introduction to the perception of auditory events. Cambridge, MA: MIT Press.

Kenderdine, M. (1931). Laughter in the preschool child. Child Development, 2, 128-130. 
LeBon, G. (1960). The crowd: A study of the popular mind. New York: Viking. (Originally published in French in 1895)

LeVelt, W. J. M. (1989). Speaking: From intention to articulation. Cambridge, MA: MIT Press.

Leventhal, H., \& CUPChiK, G. C. (1975). The informational and facilitative effects of an audience upon expression and the evaluation of humorous stimuli. Journal of Experimental Social Psychology, 11, 363-380.

Leventhal, H., \& MACE, W. (1970). The effect of laughter on evaluation of a slapstick movie. Journal of Personality, 38, 16-30.

LeVy, S. G., \& Fenley, W. F., JR. (1979). Audience size and likelihood and intensity of response during a humorous movie. Bulletin of the Psychonomic Society, 13, 409-412.

Mattingly, I. G., \& STUdderT-KenNedy, M. (EDs.) (1991). Modularity and the motor theory of speech perception. Hillsdale, NJ: Erlbaum.

McGHeE, P. E., \& Goldstein, J. H. (EDS.). (1983a). Handbook of humor research: Basic issues (Vol. 1). Berlin: Springer-Verlag.

McGheE, P. E., \& Goldstein, J. H. (EDs.) (1983b). Handbook of humor research: Applied studies (Vol. 2). Berlin: Springer-Verlag.

Morrison, J. A. (1940). A note concerning investigations on the constancy of audience laughter. Sociometry, 3, 179-185.

Nosanchuk, T. A., \& Lightstone, J. (1974). Canned laughter and public and private conformity. Journal of Personality \& Social Psychology, 29, 153-156.

Provine, R. R. (1986). Yawning as a stereotyped action pattern and releasing stimulus. Ethology, 72, 109-122.

Provine, R. R. (1989a). Contagious yawning and infant imitation. Bulletin of the Psychonomic Society, 27, 125-126.

Provine, R. R. (1989b). Faces as releasers of contagious yawning: An approach to face detection using normal human subjects. Bulletin of the Psychonomic Society, 27, 211-214.

Provine, R. R. (1990). Laughter: Social context, structure, and contagion. Society for Neuroscience Abstracts, 16(Pt. 2), 1032.

Provine, R. R., \& Fischer, K. R. (1989). Laughing, smiling, and talking: Relation to sleeping and social context in humans. Ethology, 83, 295-305.

Provine, R. R., Hamernick, H. B., \& CurChack, B. C. (1987). Yawning: Relation to sleeping and stretching in humans. Ethology, 76, 152-160.

Provine, R. R., Tate, B. C., \& Geldmacher, L. L. (1987). Yawning: No effect of $3-5 \% \mathrm{CO}_{2}, 100 \% \mathrm{O}_{2}$, and exercise. Behavioral \& Neural Biology, 48, 382-393.

Provine, R. R., \& Yong, Y. L. (in press). Laughter: A stereotyped human vocalization. Ethology.

Rankin, A. M., \& Philip, P. J. (1963). An epidemic of laughing in the Bukoba District of Tanganyika. Central African Journal of Medicine, 9, 167-170.

Sherman, L. W. (1975). An ecological study of glee in small groups of preschool children. Child Development, 46, 53-61.

SMYTH, M. M., \& FULLER, R. G. C. (1972). Effects of group laughter on responses to humorous material. Psychological Reports, 30, 132-134.

YOUNG, R. D., \& FRYE, M. (1966). Some are laughing; Some are notwhy? Psychological Reports, 18, 747-754.

ZAJONC, R. B. (1985). Emotion and facial efference: A theory reclaimed. Science, 228, 15-21.

(Manuscript received May 20, 1991.) 